\title{
Anesthesiological management of major thoracic surgery with intraoperative ECMO support in adults
}

\author{
Stephan Ziegeler ${ }^{1}$, Stefan Fischer ${ }^{2}$ \\ ${ }^{1}$ Department of Anesthesia and Intensive Care Medicine, Ibbenbueren General Hospital, Ibbenbueren, Germany; ${ }^{2}$ Department of Thoracic Surgery \\ and Lung Support, Ibbenbueren General Hospital, Ibbenbueren, Germany \\ Correspondence to: Stephan Ziegeler, MD, MA. Head of the Department of Anesthesia and Intensive Care Medicine, Ibbenbueren General Hospital, \\ Grosse Strasse 41, 49477 Ibbenbueren, Germany. Email: s.ziegeler@klinikum-ibbenbueren.de.
}

\begin{abstract}
In patients undergoing thoracic surgery procedures with pre-existing severe limitations of the pulmonary function, protective ventilation under the conditions of one-lung ventilation (OLV) often leads to a severe dysfunction of the pulmonary gas exchange. In this situation, establishing a veno-venous extracorporeal membrane oxygenation (vv-ECMO) is a sufficient and safe method to facilitate perioperative treatment of these patients. Postoperatively, patients benefit from the continuation of conscious ECMO by augmentation of necessary therapeutic procedures such as physical and respiratory therapy or early mobilization as well as healing of air leakage of the operated lung. To avoid bleeding complications, ECMO can be operated without anticoagulation intraoperatively with heparin-coating of the tube system. Postoperatively, heparin, argatroban or bivalirudin are options for anticoagulation. Enhanced Recovery Programs have been developed for thoracic surgery over the last years, containing elements like minimally invasive surgery, the use of short acting anesthetics and regional analgesia, a balanced intraoperative fluid therapy, the avoidance of nausea and vomiting as well as protective ventilation modes. Perioperative ECMO has the potential to be part of multimodal enhanced recovery approaches even for patients with severe pulmonary dysfunction. Additionally, modern concepts like non-intubated thoracic surgery can be developed further with the use of perioperative ECMO.
\end{abstract}

Keywords: Thoracic anesthesia; intraoperative extracorporeal membrane oxygenation (intraoperative ECMO)

Received: 31 August 2020; Accepted: 21 September 2020.

doi: $10.21037 /$ ccts-20-146

View this article at: http://dx.doi.org/10.21037/ccts-20-146

\section{Introduction}

Since the beginning of intrathoracic surgery general anesthesia for these procedures is challenging for the anesthetist, since it is essential to establish one-lung ventilation $(\mathrm{OLV})$ in order to achieve optimal surgical conditions. In patients with limited pulmonary function, under OLV substantial impairment of gas exchange can occur.

The most frequently used technique of lung separation is a double-lumen endotracheal tube. First concepts of OLV were described in physiologic spirometry studies in the 1870 ies. First clinical applications are documented in the 1930ies (1).
Although for intensive care medicine over the last years a large body of evidence has been published regarding mechanical ventilation, lately summarized in a German S3guideline (2), it remains unclear whether the established principles of ventilation in acute respiratory insufficiency can be transferred to intraoperative ventilation and OLV specifically. Without any doubt, multimodal approaches are necessary to anesthetize thoracic surgery patients with increasing complexity of pulmonary and general comorbidity.

This article gives an overview over the implementation of extracorporeal membrane oxygenation (ECMO) into the perioperative treatment of patients undergoing thoracic surgery. Although large clinical studies are currently not 
available, first case reports and case series as well as clinical experience are promising.

\section{Mechanical ventilation in thoracic anesthesia}

Caused by surgical tissue trauma, a ventilator-associated damage of the lung as well as reperfusion after OLV a pulmonary inflammatory response with a potential imbalance of pro- and anti-inflammatory cytokines can occur $(3,4)$, leading to a clinically relevant acute lung injury in the worst case. Therefore, during OLV protective ventilation conditions should be applied. In a current practice guideline, the following elements are recommended (5).

Although evidence remains uncertain, ventilation with low tidal volumes $(6-8 \mathrm{~mL} / \mathrm{kg})$ and a positive endexpiratory pressure (PEEP) of $5 \mathrm{cmH}_{2} \mathrm{O}$ seems to be favorable. Limitation of the peak airway pressures are also recommended. The guideline does not state any definite pressure values, though. Pressure controlled ventilation modes should be used.

To achieve the goal of protective ventilation, permissive hypercapnia with $\mathrm{PaCO}_{2}$ values of $50-70 \mathrm{mmHg}$ seems to be advantageous in analogy to ventilation concepts in acute respiratory distress syndrome patients. This approach appears problematic in patients with pre-existing pulmonary hypertension, cardiac arrhythmia or elevated intracranial pressure since hypercapnia can aggravate these comorbidities.

Alveolar recruitment maneuvers during OLV in the sense of the "open-lung" concept are proven to be useful for lung protection (6-8).

An I:E ratio of 1:1 leads to reduced airway pressures and improved pulmonary compliance as compared to a ratio of 1:2 (9). Therefore, an I:E ratio of 1:1 is recommended in OLV.

Due to the potential development of resorption atelectasis and a deception of worsening pulmonary function, in terms of the inspiratory oxygen concentration $\left(\mathrm{FiO}_{2}\right)$ the lowest possible concentration necessary to maintain adequate tissue oxygenation should be chosen. In a multivariate regression analysis, $\mathrm{FiO}_{2}$ was the only parameter associated with a higher rate of pulmonary complications with an adjusted odds ratio of 1.3 per increase of 0.1 (10).

In addition to the principles of protective ventilation of the ventilated lung during OLV, apneic oxygenation or application of a continuous positive airway pressure (CPAP) in the non-ventilated lung or the surgical limitation of pulmonary arterial blood flow to the non-ventilated lung in order to reduce shunt flow volumes represent further strategies to treat hypoxemia during OLV.

With increasing usage in acute respiratory failure and, therefore, increasing availability, implementation of a perioperative ECMO can be a very sufficient therapeutic alternative, especially in critically ill patients.

\section{Veno-venous extracorporeal membrane oxygenation (vv-ECMO) in thoracic anesthesia}

In spite of protective ventilation strategies, in patients with severely impaired pulmonary function [i.e., patients with chronic obstructive pulmonary disease (COPD)/emphysema or pre-existing pulmonary resections], often times, sufficient gas exchange cannot be achieved during OLV. In these patients, specialized concepts of anesthetic management are necessary to safely guide them through pulmonary surgery.

One very sufficient option is the perioperative establishment of a vv-ECMO. With various techniques of cannulation and a wide range of blood and sweep gas flows, it is possible to support patients from a pure decarboxylation up to a complete extracorporeal gas exchange (11). With intraoperative vv-ECMO, during OLV ultra-protective ventilation is possible without impairment of gas exchange. Even extended phases of apnea can be tolerated to generate optimal surgical conditions.

Possible indications are displayed in Table 1. Currently, there are no preoperative parameters or indices published that support the use of an intraoperative vv-ECMO. Classical parameters like the oxygenation index, lung diffusion capacity or other parameters of pulmonary function are not solely sufficient to indicate this extracorporeal support. In the author's experience, other factors like a severe over-inflation of the lung with impaired pulmonary mechanics like in COPD/emphysema may be more important. Therefore, in these patients, in the author's institution a preoperative thoracic computer tomography scan is specifically analyzed regarding the position of the diaphragm and with a quantitative emphysema analysis with a cut-off of -850 Hounsfield units. Technical aspects of the specific surgical procedure being planned, i.e., in tracheal or carinal surgery, can also be indications for the perioperative use of vv-ECMO.

Theoretical changes of the distribution volumes of anesthetic substances caused by the extracorporeal circulation are possible. The use of inhaled substances might be challenging due to very low tidal and minute volumes of ventilation or even prolonged phases of apnea. Therefore, a total intravenous anesthesia technique (i.e., 
Table 1 Possible indications for the use of a perioperative vv-ECMO

LVRS for bullous or diffuse emphysema and pulmonary hyperinflation

Pulmonary or esophageal procedures after contralateral pneumonectomy

Pulmonary surgery after lung transplantation

Obstruction of the central airways

Severe trauma of the central airways

Carinal resection

Surgery of trachea-esophageal fistula

Thoracic surgery in patients with acute respiratory distress syndrome (i.e., decortication)

Bilateral pulmonary parenchymal fistulas

vv-ECMO, veno-venous extracorporeal membrane oxygenation; LVRS, lung volume reduction surgery.

with propofol and remifentanil) with a monitoring of the depth of anesthesia (i.e., with bispectral index or entropy) is recommended when a perioperative v-ECMO is used.

The influence of ECMO on parameters like the hematocrit caused by the filling volume of the system or the $\mathrm{pH}$-value via an augmentation of $\mathrm{CO}_{2}$-elimination should be monitored with repeated blood gas analysis during the intraoperative phase.

Self-evidently, when a vv-ECMO is planned as part of the management of a thoracic surgery procedure, the potential risks and complications must be taken into account. First of all, cannula associated complications of the femoral or jugular veins (injury of the vessels, thrombosis) and disturbance of coagulation (anticoagulation, contact activation by the extracorporeal circuit) have to be expected, but immunological sequelae of an extracorporeal organ support system, that are difficult to measure, must be considered, too. The assessment of the given risk-benefit profile is also essentially dependent on defined standards and team resources of the individual institution being available for such a complex anesthetic/surgical management. An experienced team must be present inevitably for the entire course of treatment. Obviously, a patient has to be informed properly and informed written consent has to be obtained including the ECMO procedure.

\section{Clinical application}

The specific mode of vv-ECMO being used has to be adjusted to the specific needs of any individual patient. Patients with a predominantly impaired decarboxylation can be sufficiently supported by an ECMO with blood flows of 1 to $1.5 \mathrm{~L} / \mathrm{min}$. For this mode, cannulation with a 22- or 24-French double-lumen cannula via the right jugular vein or one of the femoral veins is adequate. These cannulas are placed in a Seldinger-wire supported punction technique in the majority of cases. In the case of global or predominantly hypoxemic gas exchange insufficiencies, a bi-caval cannulation with two single-lumen cannulas via the right jugular vein (17-19 French) and one of the femoral veins (19-21 French) is performed to enable blood flows of $2-4 \mathrm{~L} / \mathrm{min}$. Blood is drained over the femoral cannula and re-infused over the jugular vein in these cases. Again, principally the single-lumen cannulas can be inserted via a Seldinger-technique, especially in femoral cannulation surgical preparation of the vein has been established to be less complicated due to the size of the cannula in the author's institution. After insertion, cannula position is reassured by ultrasonography in every case to rule out jet flow into the right ventricle or recirculation in the case of bi-caval cannulation.

In addition to the blood flow, sweep gas oxygen flow is another option to enhance gas exchange independent of the cannulation technique.

After establishment of the vv-ECMO, mechanical ventilation can immediately be reduced to an ultraprotective mode with tidal volumes of $2-4 \mathrm{~mL} / \mathrm{kg}$. In the author's institution, first blood gas analysis is then performed five min after initiation of ECMO and in a 15 min rhythm thereafter. ECMO-flows (blood flow and sweep gas flow) as well as the ventilator settings $\left(\mathrm{FiO}_{2}\right.$ in particular) are adjusted accordingly.

\section{Current evidence}

Patients with severe lung emphysema can benefit from 
surgical lung volume reduction (LVRS) after careful preoperative evaluation $(12,13)$. Intraoperatively, these patients often times develop severe hypercapnia and/ or hypoxemia under OLV, especially when gas exchange limitations were already present preoperatively. In this patient group, the use of a perioperative ECMO is a good option to prevent intraoperative gas exchange disturbances and keep mechanical ventilation as protective as possible to prevent additional damage of lung tissue (14-16). After surgery, the ECMO can be further used to enable the patient to receive physiotherapy as well as breathing therapy free of stress. Also, early mobilization is enhanced, since exercise tolerance of the patient is augmented. Postoperative healing of air leakage of the lung is also facilitated by the continued use of ECMO because spontaneous breathing can be maintained or, in the case of mechanical ventilation, airway pressures can be reduced.

Another group of surgical procedures, where intraoperative use of ECMO has been reported as a safe option of intraoperative support, are complex oncologic and non-oncologic pulmonary or esophageal resections in patients with a previous contralateral pneumonectomy or in a status after lung transplantation (14,17-22).

In case reports, ECMO has been published to be used in tracheal surgery and surgery of the upper bronchial system as an alternative to high-frequency jet ventilation or cross field ventilation (23-29).

After all, ECMO is also reported as a safe option in the management of a known difficult airway (30) or central airway obstruction (31-33).

\section{Anticoagulation}

Anticoagulation for extracorporeal organ support or replacement systems, especially for the heart and lung, is challenging. On the one side, insufficient anticoagulation can lead to dysfunction of the support system or thromboembolic complications with potential lifethreatening consequences for the patient, on the other side, excessive anticoagulation can result in bleeding complications which is especially important in the perioperative use.

As a standard anticoagulant, unfractioned heparin (UFH) is recommended by the Extracorporeal Life Support Organization (ELSO). Standard monitoring of UFH therapy is the activated prothrombin time (aPTT). Especially in the perioperative context, the option of a potential antagonism of UFH with protamine in the case of excessive effect or a bleeding situation appears advantageous. The ELSO recommends a UFH-bolus of $50-100 \mathrm{IE} / \mathrm{kg}$ and a subsequent continuous infusion of at least $10-15 \mathrm{IE} / \mathrm{kg} / \mathrm{h}$ to achieve a target aPTT of $1.5-$ 2.5 times normal value (11).

Despite of anticoagulation with UFH, thrombo-embolic complications of the oxygenator are reported in about $15 \%$ in a vv-ECMO. In about the same frequency $(17 \%)$ bleeding occurs from the cannulation sites or surgical wounds (34). An aPTT of more than 70 s triples the risk of bleeding, thereby doubling the mortality (35). A reduced aPTT of 45-50 s was not able to reduce the rate of bleeding complications, increasing the risk of thrombo-embolic events to $25 \%$, though $(36,37)$.

Over the last years, alternatives to UFH were explored for the use during ECMO. Argatroban is an anticoagulant with a short half-life and can be used for anticoagulation in extracorporeal life support, especially in situations where UFH is contraindicated, i.e., in patients with heparininduced thrombocytopenia. It is monitored by aPTT also with identical target values compared to UFH. In a retrospective analysis of patients requiring ECMO being anticoagulated with argatroban or UFH, the incidence of bleeding and thromboembolic complications did not differ between the treatment groups. Interestingly, patients treated with argatroban reached target values faster and remained in the defined aPTT-corridor more stable than patients treated with UFH indicating a superior controllability of argatroban (38).

A second alternative to UFH is bivalirudine which is particularly of interest in patients with severe comorbidities since it is metabolized by serum-esterases into inactive metabolites. Only $20 \%$ of the active substance are eliminated renally. In a retrospective study, no differences regarding bleeding complications were detected in comparison to UFH (39).

A review with focus on anticoagulation in cardiac surgery summarizes pharmacology and indications of these two alternatives to UFH (40).

For anticoagulation of patients requiring ECMO perioperatively in thoracic surgery, argatroban and bivalirudin appear to be useful alternatives to UFH.

In the author's institution, no initial bolus of any anticoagulant is given for initiation of ECMO and, in the perioperative setting, continuous anticoagulation with a target aPTT of $50 \mathrm{~s}$ is started postoperatively to minimize the intraoperative risk of bleeding. This approach is supported by the heparin-coating of the ECMO-tubings 
and is based on respective case reports (41-44).

\section{Enhanced recovery after surgery (ERAS) in thoracic surgery}

In 2001, the ERAS-Society (www.erasssociety.org) was founded, developing treatment algorithms for different surgical subspecialties with the goal to enhance postoperative recovery and avoid complications $(45,46)$. For thoracic surgery, there are two current reviews summarizing ERAS-strategies $(47,48)$.

Preoperatively, a careful risk analysis, optimization of the clinical condition of the patient as well as a thorough patient information and education are critical elements of the ERAS-concept (48). Especially in patients with COPD, preoperative pulmonary rehabilitation can contribute to a better pulmonary function and quality of life after surgery (49-51).

Next to the preference of minimally invasive surgical techniques, the ERAS-recommendations contain a number of anesthesia elements.

Whilst there are no clear recommendations regarding the choice of the anesthetic technique (inhaled or total intravenous) (52-54), intraoperative volume therapy should aim for normovolemia using crystalloid solutions $(55,56)$. Furthermore, prophylaxis of postoperative nausea and vomiting as well as the prevention of intraoperative hypothermia are important factors in enhanced patient recovery (57-60).

In the postoperative period, early removal of thoracic drains (61) and a sufficient pain control achieved mainly via an epidural analgesia $(62,63)$ are the major recommendations.

A recent prospective cohort study showed in more than 400 patients undergoing surgery for primary lung cancer, that the ERAS-concept was able to reduce morbidity in a 2-year observation period (64).

Especially in patients with significant comorbidity and severely impaired pulmonary function, the perioperative use of ECMO-support offers a potential concept to facilitate large thoracic surgical procedures. In a selected patient population, it may well be part of future ERAS-protocols as a multimodal approach in the treatment of these patients.

\section{Future vision}

The implementation of minimally-invasive thoracic surgery via video-assisted thoracoscopic surgery (VATS) is one of the milestones of fast-track concepts in thoracic surgery. Compared to open surgery, a significantly lower hospital mortality, postoperative morbidity and shorter stay in the hospital could be demonstrated (65).

Taking the fast-track concept a step further, there is a growing number of reports describing VATS-procedures in a non-intubated, mostly awake patient under different techniques of regional and local anesthesia (66-69). Next to the control of the cough-reflex, hypoxemia and hypercapnia caused by the iatrogenic pneumothorax intraoperatively are the challenges of this technique. Especially in patients with impaired pulmonary function, the impaired gas exchange is a limitation of this concept. Pompeo et al. (70) report a non-intubated technique in patients undergoing minimallyinvasive LVRS procedures. Perioperative outcomes were better in the non-intubated group in comparison to the group receiving conventional anesthesia. Similar results were reported in patients undergoing resection of solitary pulmonary lesions (71).

In the particular patient group undergoing LVRS, gas exchange disturbances are a predominant problem due to the underlying disease being aggravated by the nonintubated technique. Therefore, many patients do not qualify for a non-intubated procedure. In the author's institution, in patients undergoing LVRS-procedures, the non-intubated concept has nevertheless been established by the use of a perioperative vv-ECMO. This way, a lot of patients can benefit from the advantages of the nonintubated concept even though their pulmonary function would not allow this without extracorporeal support.

\section{Conclusions}

ECMO in a vv-mode can safely be incorporated into multimodal approaches to thoracic anesthesia and surgery. In patients with an increasing grade of pulmonary impairment and comorbidity presenting for complex thoracic surgery procedures, ECMO is a tool to enable surgery and enhance postoperative recovery. Therefore, it has the potential to develop further modern concepts in thoracic anesthesia and surgery.

\section{Acknowledgments}

A similar review was recently published in Zentralblatt für Chirurgie in Germany (72). The corresponding author in this publication and would like to thank his co-authors Stephanie Rehers and Martin Beiderlinden for their 
contribution to the German article.

Funding: None.

\section{Footnote}

Provenance and Peer Review: This article was commissioned by the Guest Editors (Andrea Dell'Amore and Nizar Asadi) for the series "Mechanical Extracorporeal CardioRespiratory Supports in General Thoracic Surgery" published in Current Challenges in Thoracic Surgery. The article was sent for external peer review organized by the Guest Editors and the editorial office.

Conflicts of Interest: Both authors have completed the ICMJE uniform disclosure form (available at http:// dx.doi.org/10.21037/ccts-20-146). The series "Mechanical Extracorporeal Cardio-Respiratory Supports in General Thoracic Surgery" was commissioned by the editorial office without any funding or sponsorship. The authors have no other conflicts of interest to declare.

Ethical Statement: The authors are accountable for all aspects of the work in ensuring that questions related to the accuracy or integrity of any part of the work are appropriately investigated and resolved.

Open Access Statement: This is an Open Access article distributed in accordance with the Creative Commons Attribution-NonCommercial-NoDerivs 4.0 International License (CC BY-NC-ND 4.0), which permits the noncommercial replication and distribution of the article with the strict proviso that no changes or edits are made and the original work is properly cited (including links to both the formal publication through the relevant DOI and the license). See: https://creativecommons.org/licenses/by-nc-nd/4.0/.

\section{References}

1. McGrath B, Tennuci C, Lee G. The history of one-lung anesthesia and the double-lumen tube. J Anesth Hist 2017;3:76-86.

2. Arbeitsgemeinschaft der Wissenschaftlichen Medizinischen Fachgesellschaften (AWMF). S3-Leitlinie invasive Beatmung und Einsatz extrakorporaler Verfahren bei akuter respiratorischer Insuffizienz. 2017. Available online: https://www.awmf.org/uploads/tx_szleitlinien/0010211_S3_Invasive_Beatmung_2017-12.pdf

3. Sugasawa Y, Yamaguchi K, Kumakura S, et al. The effect of one-lung ventilation upon pulmonary inflammatory responses during lung resection. J Anesth 2011;25:170-7.

4. Lohser J, Slinger P. Lung injury after one-lung ventilation: a review of pathophysiologic mechanisms affecting the ventilated and the collapsed lung. Anesth Analg 2015;121:302-18.

5. Gao S, Zhang Z, Brunelli A, et al. The Society for translational medicine: clinical practice guidelines for mechanical ventilation management for patients undergoing lobectomy. J Thorac Dis 2017;9:3246-54.

6. Unzueta C, Tusman G, Suarez-Sipman F, et al. Alveolar recruitment improves ventilation during thoracic surgery: a randomized controlled trial. Br J Anaesth 2012;108:517-24.

7. Cinnella G, Grasso S, Natale C, et al. Physiological effects of a lung-recruitment strategy applied during one-lung ventilation. Acta Anaesthesiol Scand 2008;52:766-75.

8. Ferrando C, Mugarra A, Gutierrez A, et al. Setting individualized positive end-expiratory pressure level with a positive end-expiratory pressure decrement trial after a recruitment maneuver improves oxygenation and lung mechanics during one-lung ventilation. Anesth Analg 2014;118:657-65.

9. Kim SH, Choi YS, Lee JG, et al. Effects of a 1:1 inspiratory to expiratory ratio on respiratory mechanics and oxygenation during one-lung ventilation in the lateral decubitus position. Anaesth Intensive Care 2012;40:1016-22.

10. Okahara S, Shimizu K, Suzuki S, et al. Associations between intraoperative ventilator settings during one-lung ventilation and postoperative pulmonary complications:

a prospective observational study. BMC Anesthesiol 2018;18:13.

11. Brogan TV, Lequier L, Lorusso R, et al. Extracorporeal life support: the ELSO red book. 5th ed. Ann Arbor: ELSO, 2017.

12. Fishman A, Martinez F, Naunheim K, et al. A randomized trial comparing lung-volume-reduction surgery with medical therapy for severe emphysema. N Engl J Med 2003;348:2059-73.

13. Caviezel C, Franzen D, Weder W. Chirurgische lungenvolumenreduktion. Pneumologie 2018;72:64-78.

14. Redwan B, Ziegeler S, Freermann S, et al. Intraoperative veno-venous extracorporeal lung support in thoracic surgery: a single-center experience. Interact Cardiovasc Thorac Surg 2015;21:766-72.

15. Redwan B, Semik M, Dickgreber N, et al. Single site cannulation veno-venous extracorporeal lung support during pulmonary resection in patients with severely compromised pulmonary function. ASAIO J 
2015;61:366-9.

16. Li X, He H, Sun B. Veno-venous extracorporeal membrane oxygenation support during lung volume reduction surgery for a severe respiratory failure patient with emphysema. J Thorac Dis 2016;8:E240-3.

17. Redwan B, Ziegeler S, Dickgreber N, et al. Metastasectomy in a lung graft using high-flow venovenous extracorporeal lung support in a patient after single lung transplantation. J Thorac Cardiovasc Surg 2015;150:e79-81.

18. Xu HC, Ye P, Bao FC, et al. ECMO-assisted esophagectomy after left pneumonectomy. Int J Artif Organs 2013;36:259-62.

19. Heward E, Hayes T, Evison M et al. Extracorporeal membrane oxygenation assisted segmentectomy for metachronous lung cancer after pneumonectomy. Ann Thorac Surg 2016;102:e187-9.

20. Collins NF, Ellard L, Licari E. Veno-venous extracorporeal membrane oxygenation and apneic oxygenation for trachea-esophageal fistula repair in a previously pneumonectomized patient. Anaesth Intensive Care 2014;42:789-92.

21. Gillon SA, Toufektzian L, Harrison-Phipps K, et al. Perioperative extracorporeal membrane oxygenation to facilitate lung resection after contralateral pneumonectomy. Ann Thorac Surg 2016;101:e71-3.

22. Oey IF, Peek GJ, Firmin RK, et al. Post-pneumonectomy video-assisted thoracoscopic bullectomy using extracorporeal membrane oxygenation. Eur J Cardiothorac Surg 2001;20:874-6.

23. Radakovic D, Lazarus M, Leyh RG, et al. Venovenous extracorporeal membrane oxygenation for the management of contralateral iatrogenic bronchus perforation during lower bilobectomy. Eur J Cardiothorac Surg 2018;53:475-6.

24. Antonacci F, De Tisi C, Donadoni I, et al. Veno-venous ECMO during surgical repair of tracheal perforation: a case report. Int J Surg Case Rep 2018;42:64-6.

25. Smith IJ, Sidebotham DA, McGeorge AD, et al. Use of extracorporeal membrane oxygenation during resection of tracheal papillomatosis. Anesthesiology 2009;110:427-9.

26. Fung R, Stellios J, Bannon PG, et al. Elective use of venovenous extracorporeal membrane oxygenation and highflow nasal oxygen for resection of subtotal malignant distal airway obstruction. Anaesth Intensive Care 2017;45:88-91.

27. Lang G, Ghanim B, Hotzenecker K, et al. Extracorporeal membrane oxygenation support for complex tracheobronchial procedures. Eur J Cardiothorac Surg 2015;47:250-5.
28. Keeyapaj W, Alfirevic A. Carinal resection using an airway exchange catheter-assisted venovenous ECMO technique. Can J Anaesth 2012;59:1075-6.

29. Hoetzenecker K, Klepetko W, Keshavjee S, et al. Extracorporeal support in airway surgery. J Thorac Dis 2017;9:2108-17.

30. Malpas G, Hung O, Gilchrist A, et al. The use of extracorporeal membrane oxygenation in the anticipated difficult airway: a case report and systematic review. Can J Anaesth 2018;65:685-97.

31. Hong Y, Jo KW, Lyu J, et al. Use of venovenous extracorporeal membrane oxygenation in central airway obstruction to facilitate interventions leading to definite airway security. J Crit Care 2013;28:669-74.

32. Ko M, dos Santos PR, Machuca TN, et al. Use of singlecannula venous-venous extracorporeal life support in the management of life-threatening airway obstruction. Ann Thorac Surg 2015;99:e63-5.

33. Willms DC, Mendez R, Norman V, et al. Emergency bedside extracorporeal membrane oxygenation for rescue of acute tracheal obstruction. Respir Care 2012;57:646-9.

34. Paden ML, Conrad SA, Rycus PT, et al. Extracorporeal life support organization registry report 2012. ASAIO J 2013;59:202-10.

35. Aubron C, DePuydt J, Belon F, et al. Predicitve factors of bleeding events in adults undergoing extracorporeal membrane oxygenation. Ann Intensive Care 2016;6:97.

36. Agerstrand CL, Burkart KM, Abrams DC, et al. Blood conservation in extracorporeal membrane oxygenation for acute respiratory distress syndrome. Ann Thorac Surg 2015;99:590-5.

37. Trudzinski FC, Minko P, Rapp D, et al. Runtime and aPTT predict venous thrombosis and thromboembolism in patients on extracorporeal membrane oxygenation: a retrospective analysis. Ann Intensive Care 2016;6:66.

38. Menk M, Briem P, Weiss B, et al. Efficacy and safety of argatroban in patients with acute respiratory distress syndrome and extracorporeal lung support. Ann Intensive Care 2017;7:82.

39. Berei TJ, Lillyblad MP, Wilson KJ, et al. Evaluation of systemic heparin versus bivalirudin in adult patients supported by extracorporeal membrane oxygenation. ASAIO J 2018;64:623-9.

40. Koster A, Faraoni D, Levy JH. Argatroban and bivalirudin for perioperative anticoagulation in cardiac surgery. Anesthesiology 2018;128:390-400.

41. Bharat A, DeCamp MM. Veno-arterial extracorporeal membrane oxygenation without therapeutic 
anticoagulation for intra-operative cardiopulmonary support during lung transplantation. J Thorac Dis 2017;9:E629-31.

42. Wen PH, Chan WH, Chen YC, et al. Non-heparinized ECMO serves a rescue method in a multitrauma patient combining pulmonary contusion and nonoperative internal bleeding: a case report and literature review. World J Emerg Surg 2015;10:15.

43. Muellenbach RM, Kredel M, Kunze E, et al. Prolonged heparin-free extracorporeal membrane oxygenation in multiple injured acute respiratory distress syndrome patients with traumatic brain injury. J Trauma Acute Care Surg 2012;72:1444-7.

44. Lamb KM, Cowan SW, Evans N, et al. Successful management of bleeding complications in patients supported with extracorporeal membrane oxygenation with primary respiratory failure. Perfusion 2013;28:125-31.

45. Ljungqvist O, Scott $M$, Fearon KC. Enhanced recovery after surgery: a review. JAMA Surg 2017;152:292-8.

46. Kehlet H, Wilmore DW. Evidence-based surgical care and the evolution of fast-track surgery. Ann Surg 2008;248:189-98.

47. Piccioni F, Ragazzi R. Anesthesia and analgesia: how does the role of anesthetists change in the ERAS program for VATS lobectomy. J Vis Surg 2018;4:9.

48. Dinic VD, Stojanovic MD, Markovic D, et al. Enhanced recovery in thoracic surgery: a review. Front Med (Lausanne) 2018;5:14.

49. Vagvolgyi A, Rozgonyi Z, Kerti M, et al. Effectiveness of preoperative pulmonary rehabilitation in thoracic surgery. J Thorac Dis 2017;9:1584-91.

50. Spruit MA, Singh SJ, Garvey C, et al. An official American Thoracic Society/European Respiratory Society statement: key concepts and advances in pulmonary rehabilitation. Am J Respir Crit Care Med 2013;188:e13-64.

51. Bobbio A, Chetta A, Ampollini L, et al. Preoperative pulmonary rehabilitation in patients undergoing lung resection for non-small cell lung cancer. Eur J Cardiothorac Surg 2008;33:95-8.

52. Sun B, Wang J, Bo L, et al. Effects of volatile vs. propofolbased intravenous anesthetics on the alveolar inflammatory responses to one-lung ventilation: a meta-analysis of randomized controlled trials. J Anesth 2015;29:570-9.

53. Módolo NS, Módolo MP, Marton MA, et al. Intravenous versus inhalation anaesthesia for one-lung ventilation. Cochrane Database Syst Rev 2013;7:CD006313.

54. Beck-Schimmer B, Bonvini JM, Braun J, et al. Which anesthesia regimen is best to reduce morbidity and mortality in lung surgery? A multicenter randomized controlled trial. Anesthesiology 2016;125:313-21.

55. Assaad S, Popescu W, Perrino A. Fluid management in thoracic surgery. Curr Opin Anaesthesiol 2013;26:31-9.

56. Chau EHL, Slinger P. Perioperative fluid management for pulmonary resection surgery and esophagectomy. Semin Cardiothorac Vasc Anesth 2014;18:36-44.

57. Chandrakantan A, Glass PS. Multimodal therapies for postoperative nausea and vomiting, and pain. Br J Anaesth 2011;107:i27-40.

58. Kristensen SD, Knuuti J, Saraste A. 2014 ESC/ESA guidelines in non-cardiac surgery: cardiovascular assessment and management of the European Society of Cardiology (ESC) and the European Society of Anaesthesiology (ESA). Eur Heart J 2014;35:2383-431.

59. Devereaux PJ, Sessler DI. Cardiac complications in patients undergoing major noncardiac surgery. N Engl J Med 2015;373:2258-69.

60. Berríos-Torres SI, Umscheid CA, Bratzler DW, et al. Centers for Disease Control and Prevention Guideline for the prevention of surgical site infection, 2017. JAMA Surg 2017;152:784-91.

61. Refai M, Brunelli A, Salati M, et al. The impact of chest tube removal on pain and pulmonary function after pulmonary resection. Eur J Cardiothorac Surg 2012;41:820-2.

62. Elmore B, Nguyen V, Blank R, et al. Pain management following thoracic surgery. Thorac Surg Clin 2015;25:393-409.

63. Loop T. Fast track in thoracic surgery and anaesthesia: update of concepts. Curr Opin Anaesthesiol 2016;29:20-5.

64. Rogers LJ, Bleetman D, Messenger DE, et al. The impact of enhanced recovery after surgery (ERAS) protocol compliance on morbidity from resection for primary lung cancer. J Thorac Cardiovasc Surg 2018;155:1843-52.

65. Falcoz PE, Puyraveau M, Thomas PA, et al. Videoassisted thoracoscopic surgery versus open lobectomy for primary non-small-cell lung cancer: a propensitymatched analysis of outcome from the European Society of Thoracic Surgeon database. Eur J Cardiothorac Surg 2016;49:602-9.

66. Hung MH, Hsu HH, Cheng YJ, et al. Non-intubated thoracoscopic surgery: state of the art and future directions. J Thorac Dis 2014;6:2-9.

67. Bedetti B, Patrini D, Bertolaccini L, et al. Uniportal nonintubated thoracic surgery. J Vis Surg 2018;4:18.

68. Al-Abdullatief M, Wahood A, Al-Shirawi N, et al. Awake anaesthesia for major thoracic surgical procedures: 
an observational study. Eur J Cardiothorac Surg 2007;32:346-50.

69. Chen KC, Cheng YJ, Hung MH, et al. Nonintubated thoracoscopic lung resection: a 3-year experience with 285 cases in a single institution. J Thorac Dis 2012;4:347-51.

70. Pompeo E, Tacconi F, Mineo TC. Comparative results of non-resectional lung volume reduction performed by awake or non-awake anesthesia. Eur J Cardiothorac Surg

doi: $10.21037 /$ ccts-20-146

Cite this article as: Ziegeler S, Fischer S. Anesthesiological management of major thoracic surgery with intraoperative ECMO support in adults. Curr Chall Thorac Surg 2020. 2011;39:e51-8.

71. Pompeo E, Mineo D, Rogliani P, et al. Feasibility and results of awake thoracoscopic resection of solitary pulmonary nodules. Ann Thorac Surg 2004;78:1761-8.

72. Rehers S, Beiderlinden M, Ziegeler S. Extrakorporale Membranoxygenierung in der Thoraxchirurgie: die Sicht des Anästhesisten. Zentralbl Chir 2019;144:86-92. 